\title{
The Influence of Surface Condition on the Electrochemical Properties of ASTM F138 Steel for Biomedical Applications
}

\author{
Fernando Michelon Marques ${ }^{a *}$ (D), Alexandre da Silva Rochab (D), Giovanni Rocha Santos ${ }^{\mathrm{b}}$, \\ Mario Wolfart Juniorc ${ }^{c}$, Rodrigo Cardoso Costa ${ }^{c}$, Jane Zoppas Ferreira ${ }^{b}$ \\ ${ }^{a}$ Instituto Federal de Santa Catarina, Seminário, Chapecó, SC, Brasil \\ ${ }^{b}$ Universidade Federal do Rio Grande do Sul, Porto Alegre, RS, Brasil \\ 'Instituto Federal Catarinense, Centro, Luzerna, SC, Brasil
}

Received: December 12, 2020; Revised: November 03, 2020; Accepted: February 12, 2021

The aim of this paper was to determine the influence of machining parameters on the surface layer, and consequently on the electrochemical properties, of ASTM F138 austenitic stainless steels. Eight different surface conditions were generated in cylindrical samples by turning and polishing. The surface was characterized by surface roughness $\mathrm{R}_{\mathrm{a}}$ and $\mathrm{R}_{\mathrm{t}}$, Vickers microhardness and microstructural characteristics. Cyclic voltammetric tests were performed to evaluate the potential of repassivation and pitting. The surfaces were analyzed by Scanning Electron Microscopy after the electrochemical tests were performed. The cutting parameters were identified to have a significant influence, and the feed rate was as influential as the depth of cut. The use of polishing alone is not sufficient to ensure that a surface has good surface integrity. Even with the polishing application, usually used to produce prostheses, a significant reduction in corrosion resistance occurs if care is not taken to minimize surface machining damage. Corrosion resistance is lower and pitting nucleation is higher in the samples with no polishing and with more severe machining parameters. The tests indicated that softer machining parameters can contribute to an increase in the life of implantable components, reducing the probability of localized corrosion, as well as improving the mechanical properties of prostheses.

Keywords: Stainless steel, corrosion, machining parameters, surface integrity.

\section{Introduction}

Austenitic stainless steels are widely used in the biomedical area for manufacturing prostheses, orthotics for orthopaedic and orthodontic corrections, surgical instruments and surgical peripherals. In naval applications, the main qualities of these materials refer to their corrosion resistance in saline media, making them applicable to hydrostatic flanges of container transport vessels and submarine drive shafts. Other applications include oil prospecting systems, hydraulic flanges and gloves and turbines, among many others ${ }^{1}$.

Austenitic stainless steels have low thermal conductivity when compared to low alloy steels or bonded steels. Thus, they are susceptible to microstructural changes due to thermal and shear action during the machining process, since heat dissipation decreases through the workpiece ${ }^{2}$.

Heat generated during the cutting process can be reduced by using coated tools along with lubricating fluids. Thus, the microstructural changes of ASTM F138 stainless steel can be attenuated. However, such coolants can also contaminate the machined area of the workpiece and peripherals of the surface subject to the machining process, thus requiring further cleaning processes. Contamination can occur due to the fact that most lubricating fluids contain hydrocarbons and sulfides in their chemical composition. However, for

*e-mail: fernando.marques@ifsc.edu.br an instrument or implant to be considered applicable to the biomedical area, it must be exempt from these elements that are considered contaminants $\mathrm{s}^{3,4,5}$.

Austenitic stainless steels are considered the most difficult materials to process due to the fact that they cause excessive premature tool wear and because it is very difficult to obtain a satisfactory surface finish for the respective processes through which they are submitted ${ }^{6,7}$. Machined surfaces with low roughness values present higher resistance to localized corrosion due to smaller valleys and peaks where oxides form.

Maurotto (2017) concluded in his paper on milling that the parameters that most influence hardness variation in AISI 316L stainless steels are feed per tooth $\left(f_{z}\right)$ and tool penetration $\left(a_{p}\right)$. Moreover, this explains that the increase in hardness is caused by transforming the phase of the material's atomic structure from austenitic to alpha martensite $\left(\alpha^{\prime}\right)$ and ferrite. The same author also identified that the closer to the surface it was subjected to the material removal process, the greater the hardness in relation to the most distant points of this machining process ${ }^{8,9}$.

Bakrachevska (2014) carried out an investigation using cyclic voltammetry, performing corrosion and repassivation potential resistance tests on AISI 316 SS stainless steel pipes submitted to mechanical stresses. The author observed that the pipes submitted to most metal forming and, consequently, 
those with the most deformation, exhibited less resistance to corrosion and repassivation ${ }^{10}$.

In this paper, tests were performed to characterize the surface of ASTM F138 stainless steel round bars machined with different depths of cut and feed. Optical emission spectrometry techniques were used to determine the chemical composition, profilometry was used to measure roughness, optical microscopy to perform microstructural analysis and Brinell hardness tests and Vickers microhardness tests to determine the surface hardness and core hardness. In addition, corrosion tests were performed using cyclic voltammetry.

\section{Materials and Methods}

The material used was ASTM F138 austenitic stainless steel, which was obtained from cold-drawn bars with a diameter of $32 \mathrm{~mm}$ and a length of $600 \mathrm{~mm}$. The dimensions are similar to those used to produce femoral prostheses. The bars were solubilized at $1120^{\circ} \mathrm{C}$ for 2 hours and cooled in aqueous $\mathrm{H}_{2} \mathrm{O}$ initially at $20^{\circ} \mathrm{C}$.

The chemical composition of ASTM F138 stainless steel is shown in Table 1. Hardness measurements were performed using the Brinell method in order to characterize the material as it was received, which reached values close to $180 \mathrm{HB}$ according to the methodology required by the ASTM E-10 standard ${ }^{11}$.

The bars were turned with different cutting parameters in order to generate different samples. A Model GL240 CNC lathe with a power of $15 \mathrm{~kW}$ was used. Two depths of cut $\left[\mathrm{a}_{\mathrm{p}}\right]$ of 0.5 and $3.0 \mathrm{~mm}$ and two tool feed rates $\left[\mathrm{f}_{\mathrm{n}}\right]$ of 0.1 and $0.3 \mathrm{~mm} /$ rot were used, while the cutting speed $\left[\mathrm{v}_{\mathrm{c}}\right.$ ] was kept constant at $190 \mathrm{~m} / \mathrm{min}$. All the bars had a final diameter of $20 \mathrm{~mm}$, where the depths of cut values that were stipulated for each machining condition were removed. Afterwards, some of the machined samples underwent a polishing process, under the same conditions as hip prostheses. The purpose of polishing them was to verify whether there were still indications of machining by turning in workpieces that were polished.

The polishing process was carried out using a felt wheel, with the same principle of external cylindrical grinding, but using a $\mathrm{CNC}$ robotic manipulator (Figure 1) to keep the polishing method homogeneous by controlling the contact pressure of the grinding wheel with the contact surface. A vegetable paste consisting of abrasive based aluminium oxide with a grain size of $1 \mu \mathrm{m}$ was applied to the felt wheel.

Table 2 shows the parameters adopted for the different machining conditions. The test preceded by the letter "P" means that the surface of the machined sample went through the polishing process afterwards.

Roughness was measured for the different processing conditions. To measure roughness, a Mitutoyo brand SJ-310 model rugosimeter was used with measuring scales used in $\mathrm{R}_{\mathrm{a}}$ and $\mathrm{R}_{\mathrm{t}}[\mu \mathrm{m}]$ and using a cut-off of $0.8 \mathrm{~mm}$, with values pre-established by ABNT 4287 for turning processes ${ }^{12}$. The roughness parameter Ra corresponds to the average between peaks and valleys of the entire analyzed surface, while the parameter Rt corresponds to the measure between the highest peak and the deepest valley found during the measurements ${ }^{12}$.

Microhardness measurements of the different processing conditions were performed to obtain microhardness profiles.
Table 1. Chemical composition of ASTM F138 steel (mass -\%).

\begin{tabular}{ccccccccc}
\hline $\mathrm{C}$ & $\mathrm{Si}$ & $\mathrm{Mn}$ & $\mathrm{Cr}$ & $\mathrm{Mo}$ & $\mathrm{Ni}$ & $\mathrm{P}$ & $\mathrm{S}$ & $\mathrm{N}$ \\
\hline 0.027 & 0.342 & 1.79 & 18.448 & 2.79 & 14.147 & 0.023 & 0.001 & 0.087 \\
\hline
\end{tabular}

Table 2. Cutting tests and number of tests.

\begin{tabular}{ccccc}
\hline $\begin{array}{c}\text { Test/Test } \\
\text { Parameter }\end{array}$ & $\mathrm{v}_{\mathrm{c}}[\mathrm{m} / \mathrm{min}]$ & $\mathrm{f}_{\mathrm{n}}[\mathrm{mm} / \mathrm{rot}]$ & $\mathrm{a}_{\mathrm{p}}[\mathrm{mm}]$ & Polishing \\
\hline Test 1 & 190 & 0.1 & 0.5 & No \\
\hline Test 2 & 190 & 0.1 & 3.0 & No \\
\hline Test 3 & 190 & 0.3 & 0.5 & No \\
\hline Test 4 & 190 & 0.3 & 3.0 & No \\
\hline Test 1 P & 190 & 0.1 & 0.5 & Yes \\
\hline Test 2 P & 190 & 0.1 & 3.0 & Yes \\
\hline Test 3 P & 190 & 0.3 & 0.5 & Yes \\
\hline Test 4 P & 190 & 0.3 & 3.0 & Yes \\
\hline
\end{tabular}

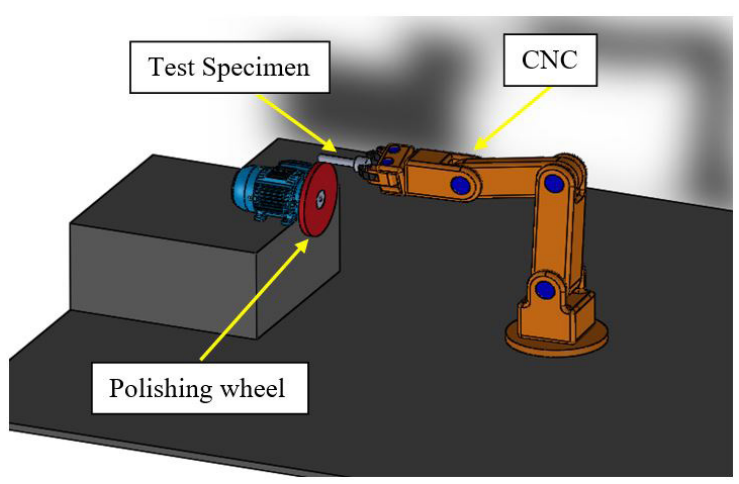

Figure 1. Sample polishing process.

An Equilam EQMHV-2000Z model microdurometer with a load of $0.01 \mathrm{~N}$ and load application time of 15 seconds was used. The measurement parameters were in accordance with the guidelines in the ASTM E384 standard $^{13}$.

In order to evaluate the electrochemical characteristics of the surfaces against corrosion, cyclic voltammetry tests were carried out by checking repassivation according to the machining condition. The test medium was the solution of $0.5 \mathrm{M}_{2} \mathrm{H}_{2} \mathrm{SO}_{4}+0.01 \mathrm{M} \mathrm{KSCN}$ at $\mathrm{pH} 0$ and a temperature of $20{ }^{\circ} \mathrm{C}$. The scanning range was from $-400 \mathrm{mV}$ to $+400 \mathrm{mV}$, and the scanning speed was $0.016 \mathrm{~V} / \mathrm{s}$. Preliminary tests were carried out with several scanning speeds lower than those mentioned in the work, and which yielded the same result for all samples. Therefore, we opted for the test that would use the shortest possible time, as long as it obtained reliable results. The values of open circuit potential (OCP) ranged from 0.16 to $0.39 \mathrm{~V}$, being considered close values for all samples.

A three-electrode system with a saturated calomel electrode (SCE) as the reference electrode and a platinum plate as the counter electrode was used to conduct the electrochemical tests, and all the potentials in this study were versus SCE. The electrochemical workstation AUTOLAB PGSTAT 302 that is controlled by acomputer was used to measure the voltametric curves of the steels. The exposure area for the test was approximately $2.0 \mathrm{~cm}^{2}$. 
The justification for the use of the voltammetry test solution is based on AQUINO (2009) and CHENG (2019), which affirms the use of this solution as being more appropriate for the formation of corrosion pits during tests on stainless steel, accelerating the tests ${ }^{14,15}$.

\section{Results and Discussion}

\subsection{Roughness}

The values found during the process of measuring the roughness of the samples are shown in Figures 2 and 3 which represent parameters $\mathrm{R}_{\mathrm{a}}$ and $\mathrm{R}_{\mathrm{t}, \mathrm{r}}$ respectively.

Initially, in Figure 2, it can be observed that polishing after machining significantly reduced the surface roughness of the samples. However, for the more severe conditions of machining, this reduction is percentually lower and the roughness remains high. The results shown in Figure 2 indicate, as expected, due to the softer machining conditions, test 1 and $1 \mathrm{P}$ as being those that generate the lowest mean roughness values, followed by test 2 . On the other hand, the greatest roughness was found for test 3 and 4 (higher tool feed rate).

As shown in Figure 3, test 4 shows higher values of total roughness $\left(R_{t}\right)$ as it is more severe due to the tool feed rates of $0.3 \mathrm{~mm} /$ rot and $3.0 \mathrm{~mm}$ depth of cut.

In a study on machined surfaces, RAJAGURU (2018) shows that higher roughness values are obtained with higher values of tool feed rates, and the higher the shear stresses caused by the increased depth of cuts, the higher the vibration indexes in the tool/workpiece assembly, also increasing the roughness of the machined surface. The same tendencies were observed in the present work, that is, with higher tool feed rates and greater depths of cut, there is a considerable worsening of the roughness, which is already expected since the objective is to evaluate the impact on the electrochemical properties of the surface against the corrosive medium ${ }^{16}$.

\subsection{Microhardness profile}

Figure 4 shows the results of the microhardness profiles at test 1 and $1 \mathrm{P}$ after the machining process with values of $0.1 \mathrm{~mm} /$ rot of feed and $0.5 \mathrm{~mm}$ of depth of cut. For both tests, it can be observed that there is a stabilization range of the hardness from a distance of $0.06 \mathrm{~mm}$, when there is no more material hardening.

The maximum hardness values found are in the region closest to the edge of the samples and are close to $380 \mathrm{HV}$, the region where the stabilization of the hardness values occur is from $0.06 \mathrm{~mm}$ and with values close to $280 \mathrm{HV}$. Polishing did not significantly affect the surface microhardness values, since the amount of material removed by polishing is insignificant compared to the altered surface region.

Figure 5 shows the microhardness profile for Test 2 and $2 \mathrm{P}\left(\mathrm{f}_{\mathrm{n}}=0.1 \mathrm{~mm} / \mathrm{rot}\right.$ and $\left.\mathrm{a}_{\mathrm{p}}=3.0 \mathrm{~mm}\right)$. It can be seen that there is an increase of hardness in relation to test 1 and test 1P. The maximum hardness values of samples 1 and $1 \mathrm{P}$ were in the region closest to the edge and near $380 \mathrm{HV}$, samples 2 and 2P showed values between 420 and $440 \mathrm{HV}$. It can also be

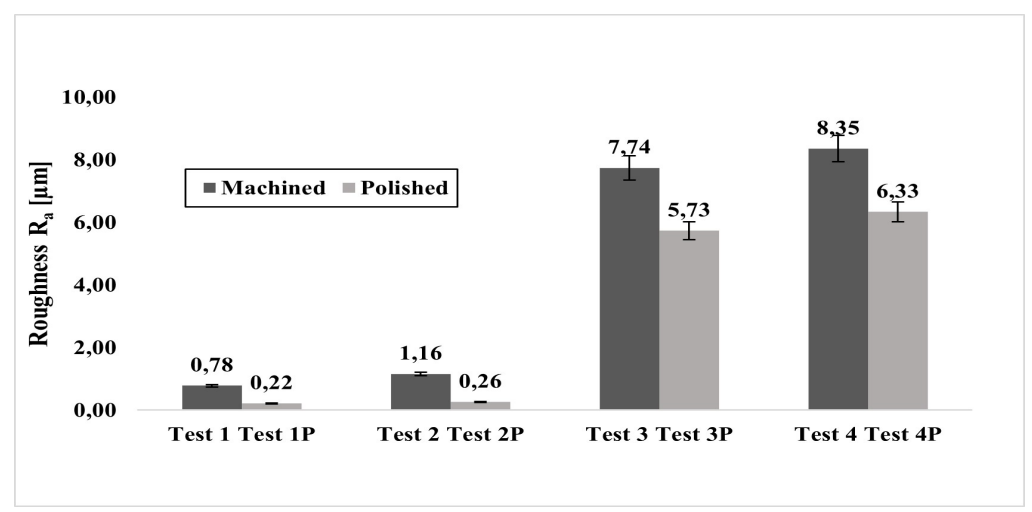

Figure 2. Roughness values of the samples.

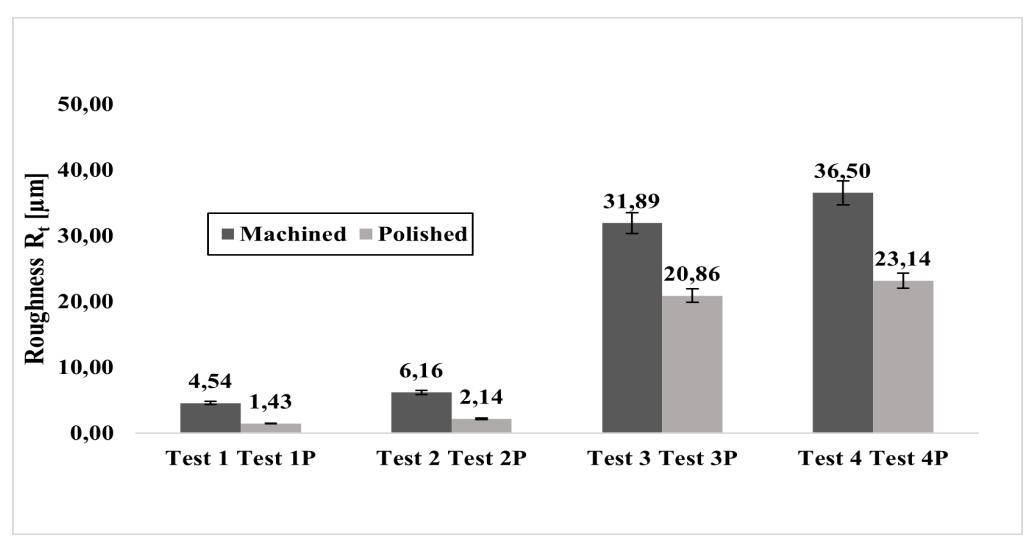

Figure 3. roughness values of the samples. 


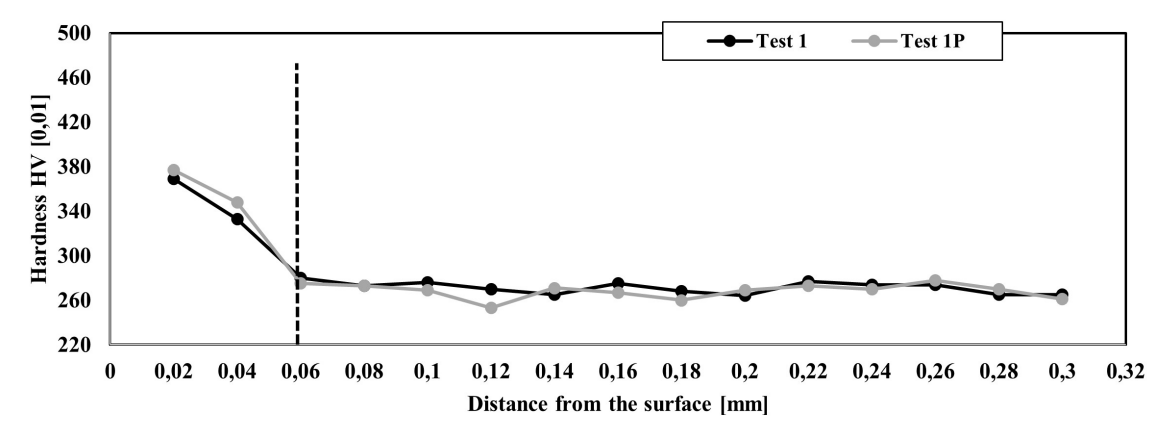

Figure 4. Hardness values of samples - Test 1 and Test 1P.

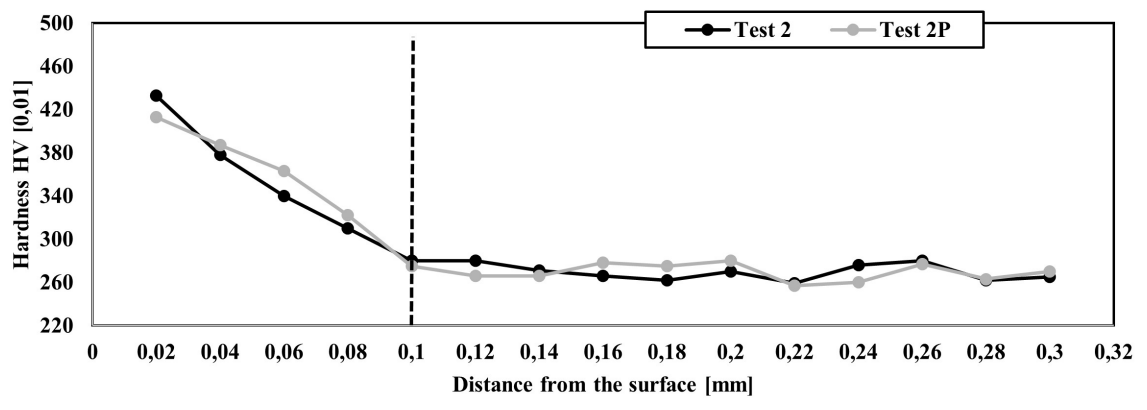

Figure 5. Hardness values of samples - Test 2 and Test 2P

observed that the point where the hardness stability occurs is from $0.1 \mathrm{~mm}$ depth, for both test 2 and test $2 \mathrm{P}$. Thus, it is estimated that the machining process affected the steel structure up to $0.1 \mathrm{~mm}$ deep and that the polishing process did not influence the hardness values. The higher hardness values found for tests 2 and $2 \mathrm{P}$ in relation to tests 1 and $1 \mathrm{P}$ are due to the higher penetration value of the tool which causes greater plastic deformation in the machined bars.

Figure 6 shows the microhardness profiles for test 3 and $3 \mathrm{P}\left(\mathrm{f}_{\mathrm{n}}=0.3 \mathrm{~mm} /\right.$ rot and $\left.\mathrm{a}_{\mathrm{p}}=0.5 \mathrm{~mm}\right)$. There was no significant increase in the depth at which hardness is increased. It should be noted that the machining parameters become more severe regarding the tool feed rate, however with lower tool penetration values.

The distance from the surface where the hardness stability begins is seen from $0.08 \mathrm{~mm}$ and showed hardness values of the region closest to the edge between 410 and $430 \mathrm{HV}$, similar to the values of tests 2 and $2 \mathrm{P}$.

Polishing the sample did not significantly influence the hardness values, even with a reduction from $\mathrm{a}_{\mathrm{p}}$ to $0.5 \mathrm{~mm}$, but increasing from $\mathrm{f}_{\mathrm{n}}$ to $0.3 \mathrm{~mm} / \mathrm{rot}$.

It can be observed that the feed rate also influences the surface hardness of the steel, and in terms of the analyzed values, it is less effective than $a_{p}$.

Figure 7 shows the microhardness profile results for Test 4 and $4 \mathrm{P}\left(\mathrm{f}_{\mathrm{n}}=0.3 \mathrm{~mm} /\right.$ rot and $\left.\mathrm{a}_{\mathrm{p}}=3.0 \mathrm{~mm}\right)$. The parameters used in these tests were most influential in increasing the hardness values measured on the surface of the material. It can be observed that the point where the average hardness constancy occurs is from $0.18 \mathrm{~mm}$, and the largest distance is found from all the tests performed. The region closest to the edge showed a hardness value of $480 \mathrm{HV}$ for the machined sample and $450 \mathrm{HV}$ for the polished sample, and it was considered that the polishing process influenced the reduction of hardness values. The values found up to the region of hardness stabilization, between 260 and $300 \mathrm{HV}$, showed similar behavior for the machined and polished samples.

In his research conducted on machining, MAUROTTO (2017) identified that during the machining of AISI 316L, higher feed rates provide greater depths of layer deformation, explaining this by the severe effort of cutting material, thus leading to austenitic grain sliding that formed martensite induced by $\alpha$ ' deformation. The increase in hardness $(460 \mathrm{HV})$ also occurs on the surface of the samples in relation to the core $(300 \mathrm{HV})$. Another characteristic was that the formation of $\alpha$ ' martensite was also found with more severe values of $a_{p}$, explaining the difficulty of heat dissipation of the steels used and the generation of thermal input in the machining ${ }^{8}$.

The results found in the hardness measurements of the samples are in agreement with results found by other researchers (MAUROTTO and RAJAGURU) regarding the increase in the regions near the edges of the samples. Except for tests 1 and $1 \mathrm{P}$, the other tests generated hardness values from $380 \mathrm{HV} 0.01$ in the measurements closest to the edge of the samples and decreased inversely proportional to the distance from the edge $\mathrm{e}^{9,16}$.

Table 3 shows the summary of the obtained results of surface hardness found and the depth affected by the machining according to each condition. 


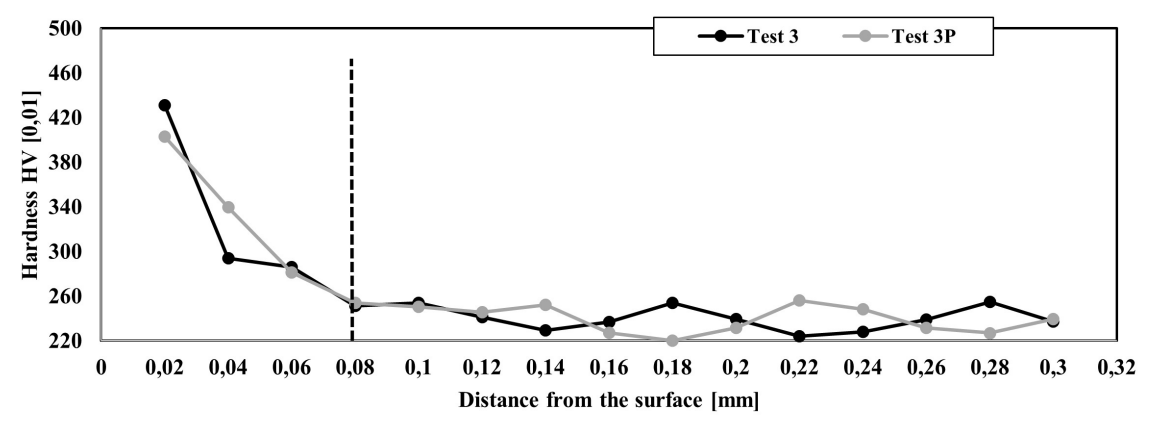

Figure 6. Hardness values of samples - Test 3 and Test $3 \mathrm{P}$.

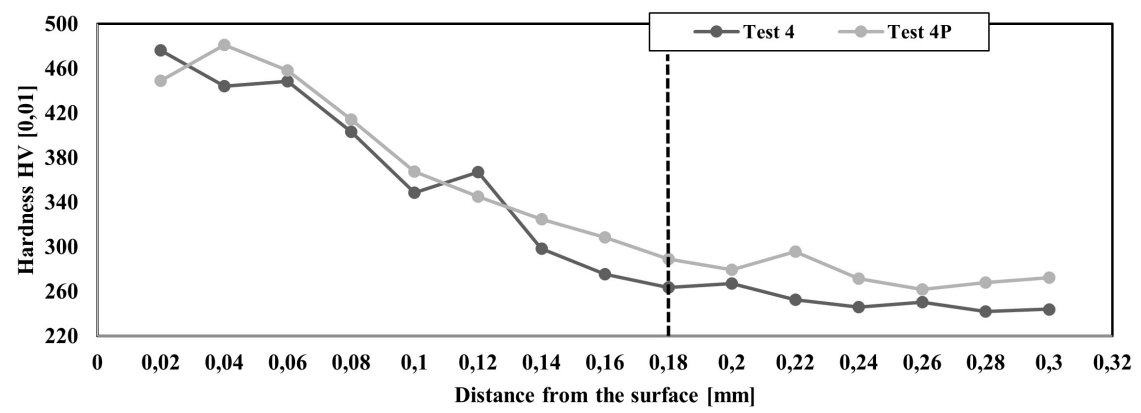

Figure 7. Hardness values of samples - Test 4 and Test 4P.

Table 3. Summary of hardness and depth results affected by machining

\begin{tabular}{ccc}
\hline Tests & $\begin{array}{c}\text { Surface hardness } \\
{\left[\mathrm{HV}_{0.01}\right]}\end{array}$ & $\begin{array}{c}\text { Depth affected } \\
{[\mathrm{mm}]}\end{array}$ \\
\hline Test 1 & 380 & 0.06 \\
\hline Test 2 & 440 & 0.1 \\
\hline Test 3 & 430 & 0.08 \\
\hline Test 4 & 480 & 0.18 \\
\hline Test 1P & 380 & 0.06 \\
\hline Test 2P & 420 & 0.1 \\
\hline Test 3P & 410 & 0.08 \\
\hline Test 4P & 450 & 0.18 \\
\hline
\end{tabular}

It can be observed that the tool feed rate increases the surface hardness value, Test 3 , however the depth of cut obtained a greater thickness of the layer affected, Test 2 , however the association of the more severe values of machining parameters, Test 4 , was the that one obtained higher hardness and depth affected values.

\subsection{Microstructure}

Figures 8 to 11 show the microstructures of the surface region (cross sections) of the bars machined under the different conditions.

It can be observed in Figures $8 \mathrm{a}$ and $8 \mathrm{~b}$, respectively, for Test 1 and 1P, that the surface material undergoes plastic deformation, as seen by the deformed grains (indicated by the arrow).

The polishing proved to be effective for this parameter conjugate, since it removed the surface material. Comparing
Test 1 to Test 1P, it has a plastic deformation of the turning process.

The representations of Tests 1 and $1 \mathrm{P}$ show that the grain boundaries of the material deformed, and that the deformation became less apparent as the distancing of the sample surface occurred, perceived by the more rounded shape rather than "elongated" material.

Figure $9 \mathrm{a}$ and $9 \mathrm{~b}$ shows the images of Test 2 and $2 \mathrm{P}$, where more elongated grain boundaries at larger distances from the edge of the samples can be observed, compared to Tests 1 and $1 \mathrm{P}$, respectively.

Figure 10 shows the microstructures of Test 3 and Test $3 P$ samples, where $f_{n}=0.3 \mathrm{~mm} /$ rot. It can be observed that there was a greater deformation of the grains of the samples with respect to tests $1,1 \mathrm{P}, 2$ and $2 \mathrm{P}$, making them in a more elongated aspect, and that both tests 3 and 3P, Figure 10a and 10b presented a greater depth of the deformed layer.

Figure 11 shows the microstructures resulting from tests 4 and 4P, where the association of larger machining parameters can be observed that affected the surface of the sample in relation to grain deformation. This evaluation is determined by the distance from the surface that was affected to the sample.

It is well known that austenitic steels, in particular ASTM F138, exhibit transformation from austenite $(\gamma)$ phases to martensite $\left(\alpha^{\prime}\right)$, which is induced by deformation when subjected to high shear stresses that cause crystalline planes to slide, and that the formation of ferrite does not occur in this type of material. 


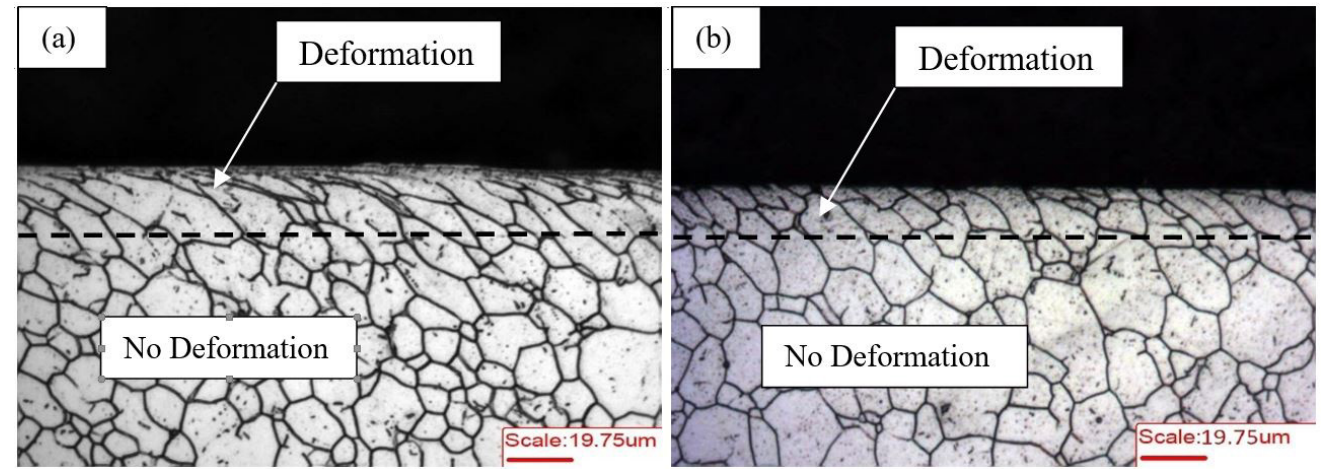

Figure 8. Sample Test 1 (a) machined and (b) machined and polished. Electrolytic attack with $60 \% \mathrm{HNO}_{3} 40 \%_{0} \mathrm{H}_{2} \mathrm{O}$.
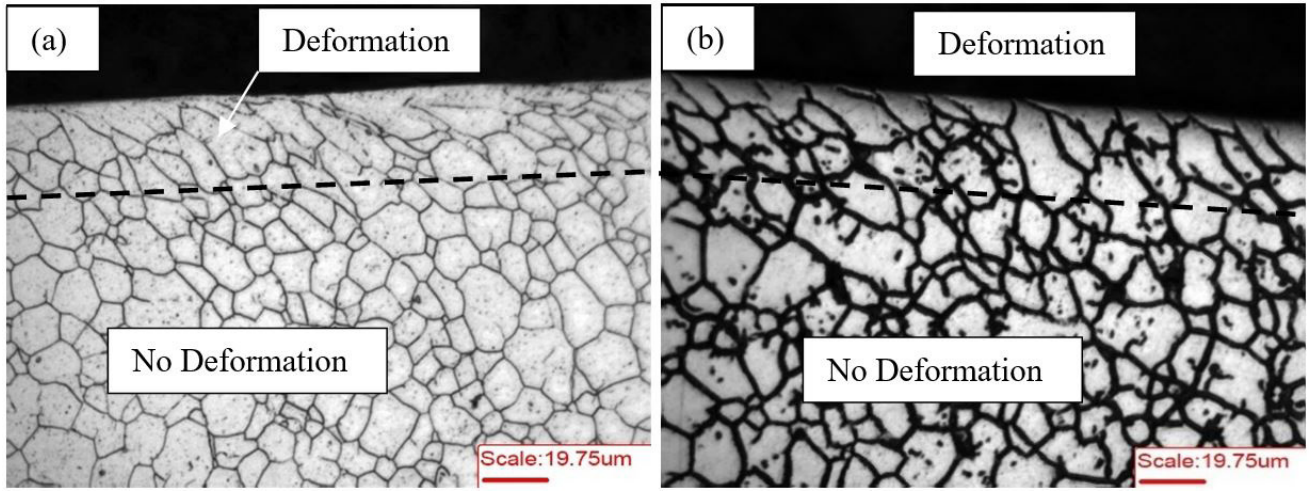

Figure 9. Sample Test 2 (a) machined and (b) machined and polished. Electrolytic attack with $60 \% \mathrm{HNO}_{3} 40 \% \mathrm{H}_{2} \mathrm{O}$.
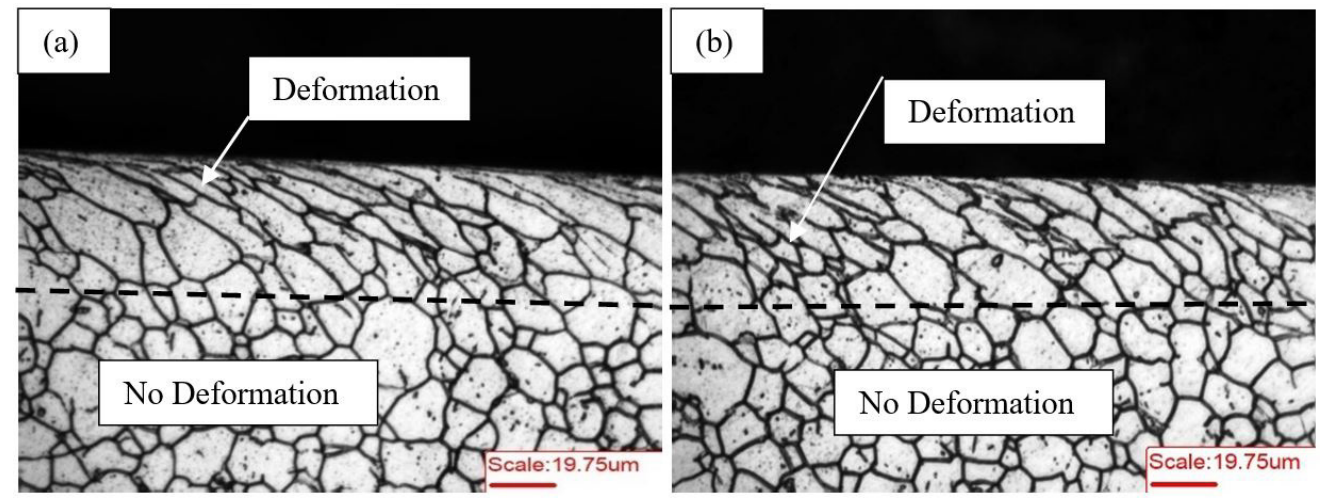

Figure 10. Sample Tests 3 (a) machined and (b) machined and polished. Electrolytic attack with $60 \% \mathrm{HNO}_{3} 40 \% \mathrm{H}_{2} \mathrm{O}$.
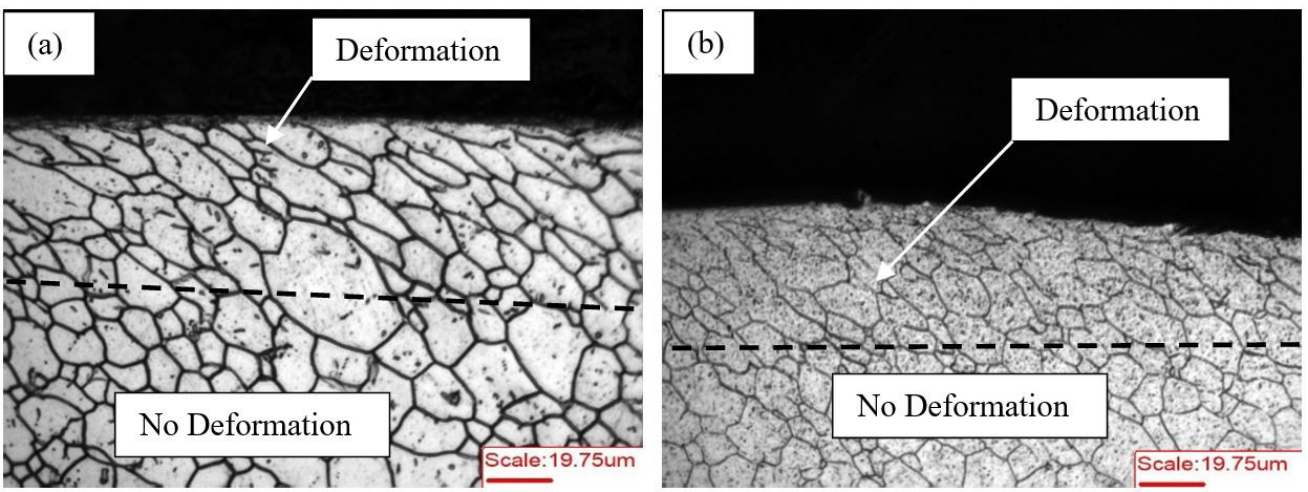

Figure 11. Sample Test (a) machined and (b) machined and polished. Electrolytic attack with $60 \% \mathrm{HNO}_{3} 40 \% \mathrm{H}_{2} \mathrm{O}$. 
In samples without polishing, a thin layer at the edge of the samples can be observed where there is a high density of grain boundaries that were attacked by the $60 \% \mathrm{HNO}_{3}$ and $40 \% \mathrm{H}_{2} \mathrm{O}$ reagent. These grain limits indicate the possibility of martensite formation occurring on the surface, but they do not present great depths, and that the hardness values found in all the samples do not indicate the presence of martensitic structure in the tests performed from $0.02 \mathrm{~mm}$ of distance from the edges of the samples.

In the polished samples, the same behavior of the surface was not detected in relation to the reagent attack, indicating that the polishing removed the martensite layer, but in values below those of the hardness measurement, they were identified in the Vickers hardness tests.

In a study on low carbon martensitic stainless steels $(0.06 \%)$ conducted by BISSEY-BRETON (2016), the author found a phase change in a $0.01 \mathrm{~mm}$ layer of the surface with the tool feed rate variation $(0.1$ and $0.3 \mathrm{~mm} / \mathrm{rot})$. The hardness values increased in this region (430 HV0.01) in relation to the sample cores (370 HV0.01). This layer was characterized by the great concentration of grain boundaries, as the XRD results were not able to detect the thin martensitic layer ${ }^{17}$.

\subsection{Voltammetry}

The results of the cyclic voltammetry tests are shown in Figures 12-15. The analysis of these curves aims to obtain responses regarding the influence of the machining conditions applied in the repassivation process of the ASTM F138 stainless steels.

Concerning the repassivation potential, Figure 12 illustrates that both situations show positive results regarding corrosion resistance, since the rupture of the passivating film does not occur until reaching the maximum point of the potential where the potential reversal occurs. During the reversal of the potential, the hysteresis of the voltammetry curve did not occur, characterizing the non-breaking of the passivating film, and consequently, nor the nucleation of some possible pitting. Reconstitution of the passivating film occurs prior to test $1 \mathrm{P}$ regarding test 1 , thus identifying that the surface of the material has been transferred before to the polished surface rather than the machined one, in which repassivation occurred at a potential of $0.15 \mathrm{~V}$ occurring for the polished sample, whereas it was $-0.08 \mathrm{~V}$ for test 1 .

At the beginning of the anode zone for test 1, a variation of the rise of the curve occurs, whereas test $1 \mathrm{P}$ does not

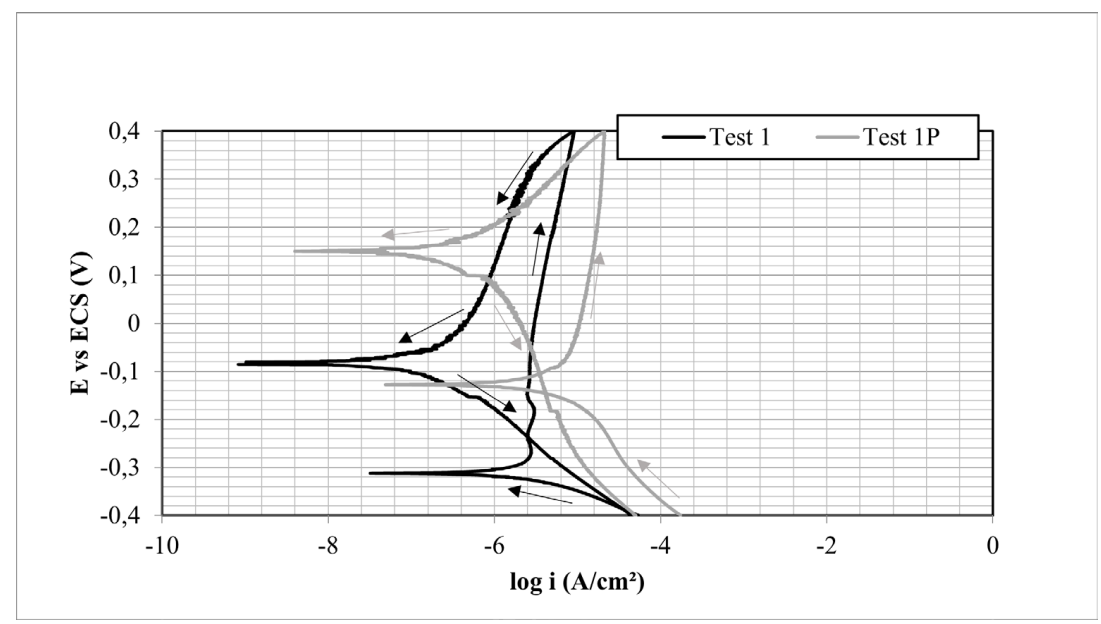

Figure 12. Cyclic voltammetric curves for tests 1 and $1 \mathrm{P}$.

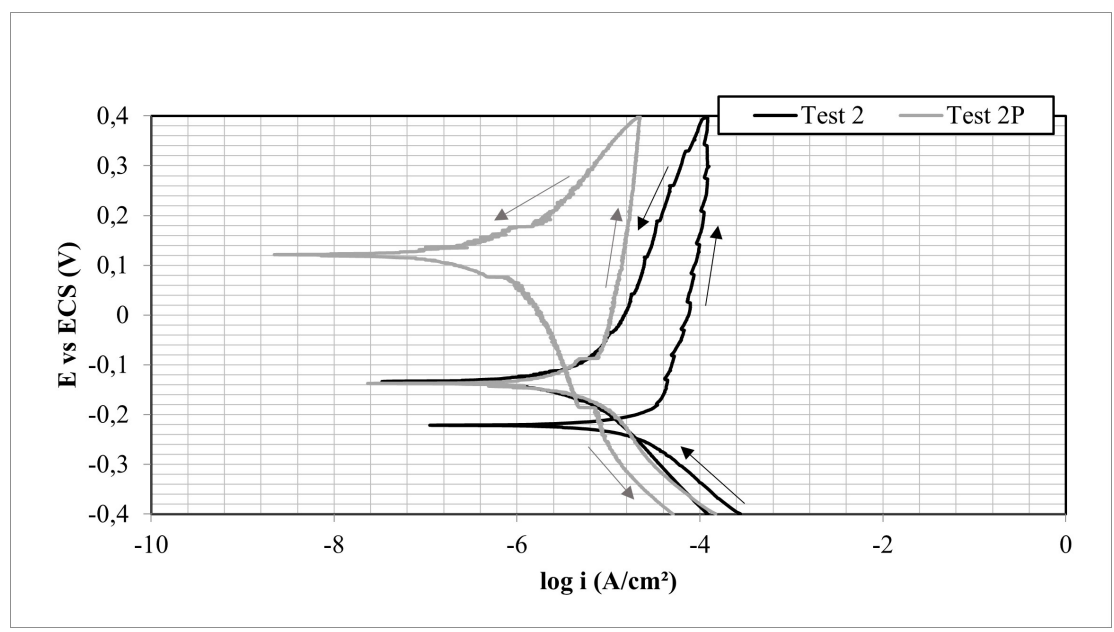

Figure 13. Cyclic voltammetric curves for tests 2 and $2 \mathrm{P}$. 


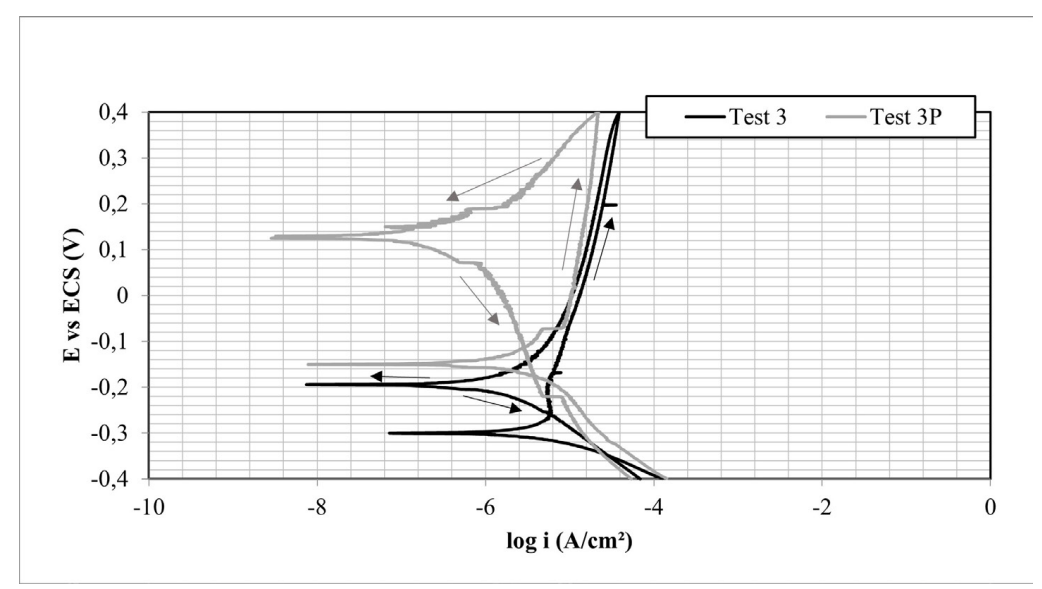

Figure 14. Cyclic voltammetric curves for tests 3 and $3 P$.

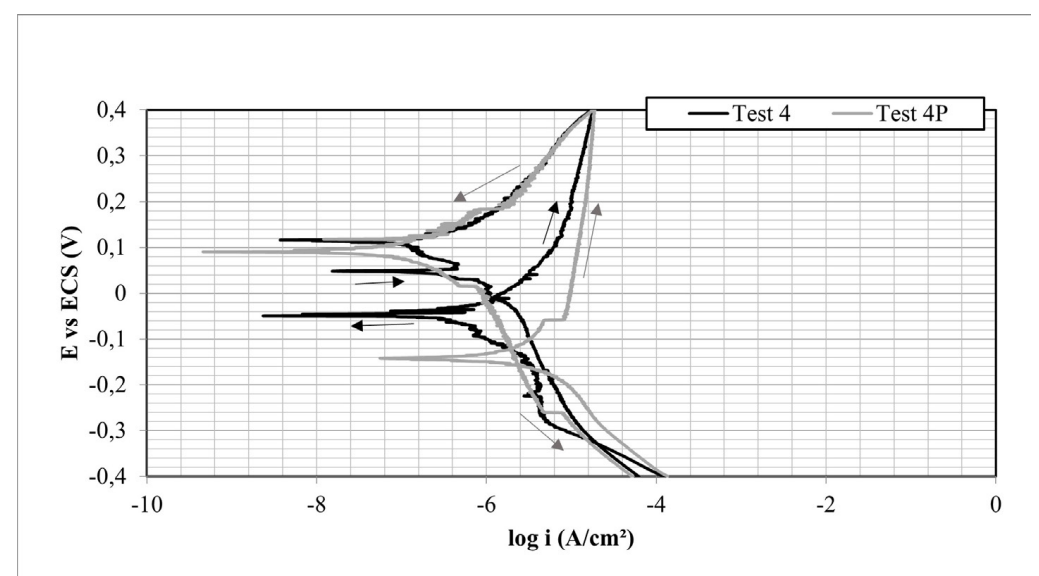

Figure 15. Cyclic voltammetric curves for tests 4 and $4 \mathrm{P}$

present any irregular behavior. This fact can be explained by the occurrence of the beginning of pitting nucleation, but that did not happen.

By changing the depth of cut values, other polarization curves were also generated, as shown in Figure 13 for tests 2 and $2 \mathrm{P}$. In these voltammetry tests, the cathodic and passive zone formation occurs with a higher current value for test 2 , characterizing that the current action was more damaging in the sample that was only machined, and its propagation, characterized by the rise of the curve, occurs in an unstable way. This can be explained by the attempt to break the passive film, but pitting nucleation does not occur, as the hysteresis occurs at a current value lower than the end of the potential rise, and the cathodic zone ends with a value of potential near $-0.13 \mathrm{~V}$.

Test $2 \mathrm{P}$ is characterized by a rise in the curve with lower current values compared to test 2 . Its hysteresis also occurs with the same tendency, but the formation of the passivating film occurs at $0.12 \mathrm{~V}$, characterizing a surface that is more resistant to the nucleation process of pitting corrosion.

Samples of tests 3 and 3P (Figure 14) show behaviors characteristic of pitting formation. In the curve of test 3 , it can be observed that during the formation of the anodic zone, the discrete current variation occurs, before starting the increase of the potential with an increase in the current. While the potential is increasing, two interruptions of continuity occur, which can be identified as the breaking of the passivating film. When the curve is returning, the proximity compared to the rise of the potential itself shows a difficulty in maintaining the passivating film, up to the maximum point of passivation potential.

In contrast to the analysis of test 3 , the $3 \mathrm{P}$ test, after forming the corrosion potential and the beginning of the formation of the passive region, the active region presents a non-continuity but does not affect the formation of the passive region. Its return occurs with a lower current value than test 3 and its repassivation potential is at levels higher than those previously identified. Thus, the $3 \mathrm{P}$ test has a higher repassivation potential than test 3 .

Figure 15 shows the cyclic voltammetry curve of the cutting parameters, which are considered to be more severe, representing tests 4 and $4 \mathrm{P}$.

The sample that was only subjected to the turning process presents an atypical behavior among the other curves analyzed at the beginning, until the formation of its corrosion potential. Afterwards, the passive region represents little of the curve 
since the active region is the one that appears more up to the potential of $0.2 \mathrm{~V}$ when the curve increases. From this value onwards, the passive region starts. When the corrosion potential decreases, its maximum repassivation point occurs at values close to $0.11 \mathrm{~V}$.

The polished sample called the 4P test has a corrosion potential below the unpolished one. Its active curve is lower and less representative where the passivation region with a low current increase value has already started. When the corrosion potential starts declining, the current value also decreases to the point of $0.8 \mathrm{~V}$, where the maximum point of repassivation occurs, following the cathodic region and ending the voltammetry test.

During the test, the two curves showed no continuities, but at no point is pitting formation and nucleation clear. Moreover, the hysteresis are all at current values lower than the passivation points, characterizing a high resistance to corrosion and formation of passivating films after being subjected to severe electrochemical attacks.

In all the cyclic voltammetric tests, the samples showed a definite active zone formation and a passivation zone during the increase of potential. While their potential was decreasing, they showed repassivation capacity, however the respective samples of tests $3,3 \mathrm{P}, 4$ and $4 \mathrm{P}$ showed a greater tendency to break the passive film and it was difficult to reestablish its potential.

\subsection{Scanning electron microscopy}

Figures 16-19 show the images of the surfaces of the samples after cyclic voltammetry. The points where the formation of corrosion pits occurred can be observed.

Figure 16a shows test 1 . The machining marks left by the turning process can be observed, as well as pitting corrosion originating from the cyclic voltammetry process. Compared with Figure 16b, which relates to test 1P, it can be observed that the machining marks are less apparent due to the polishing process. Figure $16 \mathrm{~b}$ shows the corrosion pits, but they are smaller in size than those in Figure 16a.

Figure 16b shows that even with the polishing, the machining marks were not totally removed, but were softened. This is in accordance with the roughness values measured on both surfaces.
Figure 17a shows the surface resulting from the tests of test 2 . It can be observed that the machining lines are present and that they have the same distance between them, similar to those observed in Figure 16a. Thus, it can be seen that the tool feed rate was the same for the two samples. Moreover, there is evidence of adherence in the machining lines, which can be better identified and denominated as machining residues in Figure 17a. The possible explanation for the adhesion of the material can be attributed to the increase of material to be removed and due to more work done in the material which generated a greater amount of heat to the point that it reduced the ductility of the material, thus making the chipping process difficult and forming the machining residues.

As well as evidence of adhered material, Figure 17a shows pitting formation. The explanation is based on the hypothesis that the phase change of the material during the machining process was more prominent in the areas where the removal of the material was not as efficient (adhered chipping), thus allowing material with structure other than austenite to have remained adhered on the analyzed surface, causing the formation of pitting corrosion, since austenite is considered a phase which is resistant to pitting corrosion.

Figure $17 \mathrm{~b}$ illustrates the sample surface of the $2 \mathrm{P}$ test, and the effectiveness of the polishing due to the absence of machining marks can be seen. However, Figure 17 shows that pitting corrosion was formed, and at a larger proportion than that found in Figure 16.

Figures $18 \mathrm{a}$ and $8 \mathrm{~b}$ show the surface of the samples of tests 3 and 3P, respectively. It can be observed that the machining lines are far from each other in tests 1 and 2, and adhered material can be clearly seen. Pitting corrosion can be observed in Figure 18a, and it is close to the machining lines.

In Figure 18b, even after the polishing process, the machining lines can be identified, thus showing that the turning process derived more protruding marks than the other tests analyzed so far, and pitting corrosion is also identified. Figure $18 \mathrm{~b}$ shows one of the pits on the sample surface, and near a machining line.

Figure 19 is related to test 4 and 4P, where a similarity of the distance between the machining lines of test 3 can be seen. Once more, the non-linearity of the lines can be identified due to the material adhered on them. Pitting corrosion can be observed in Figure 19a and Figure 19b.
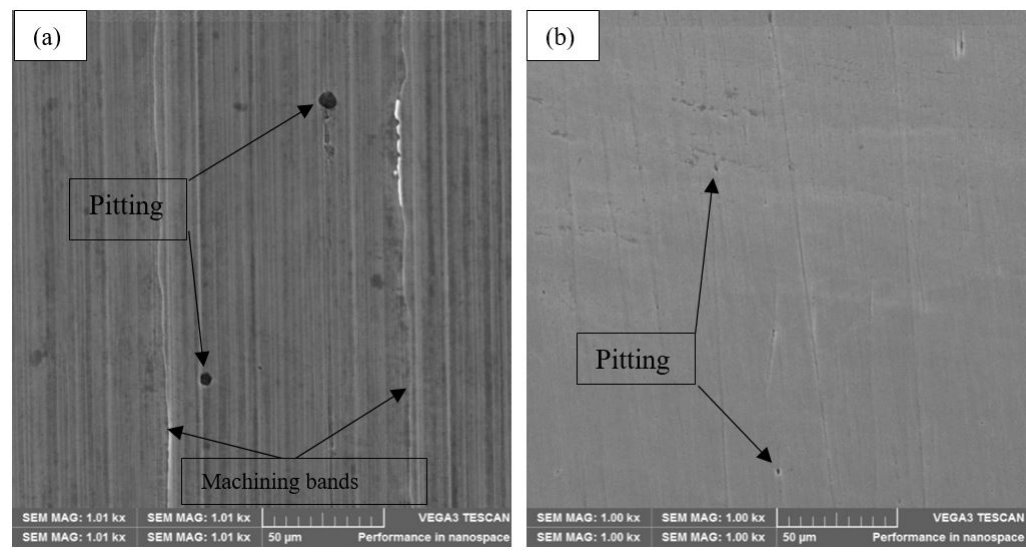

Figure 16. Samples of tests 1 (a) and $1 \mathrm{P}$ (b) with 1000X magnification. 
Figure $19 \mathrm{~b}$ shows that the polishing process removed some of the material that was on the machining lines, and that there are more pits than in the other samples. Figure $19 \mathrm{~b}$ shows that in addition to the larger pits, evidence of pitting formation was discontinued at the end of the polarization test.

HONG (2018) identified pitting corrosion formation in stainless steels after being subjected to deformation and found that the pits were not deep but are relatively wider.
This can be explained by the phase change, reducing the surface corrosion resistance to the deeper layers of the material tested ${ }^{18}$.

The corrosion pits found in tests 4 to $4 \mathrm{P}$ show that the surface was affected after polishing, reducing the number of corrosion pits. However, by comparing test 1 to test 4 , it is clear that the machining efforts provided higher rates of corrosion pits.
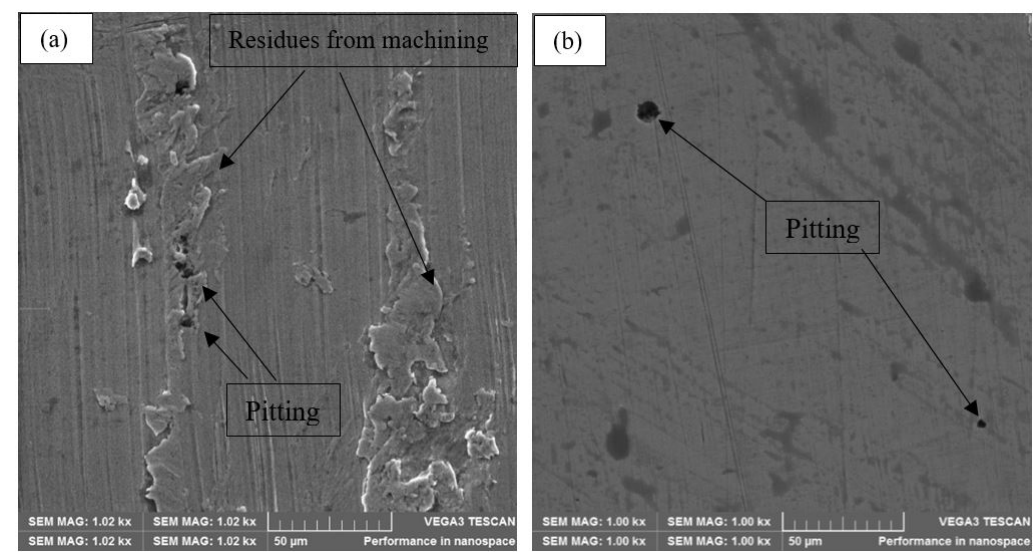

Figure 17. Samples of tests 2 (a) and $2 \mathrm{P}(\mathrm{b})$ with $1000 \mathrm{X}$ magnification.
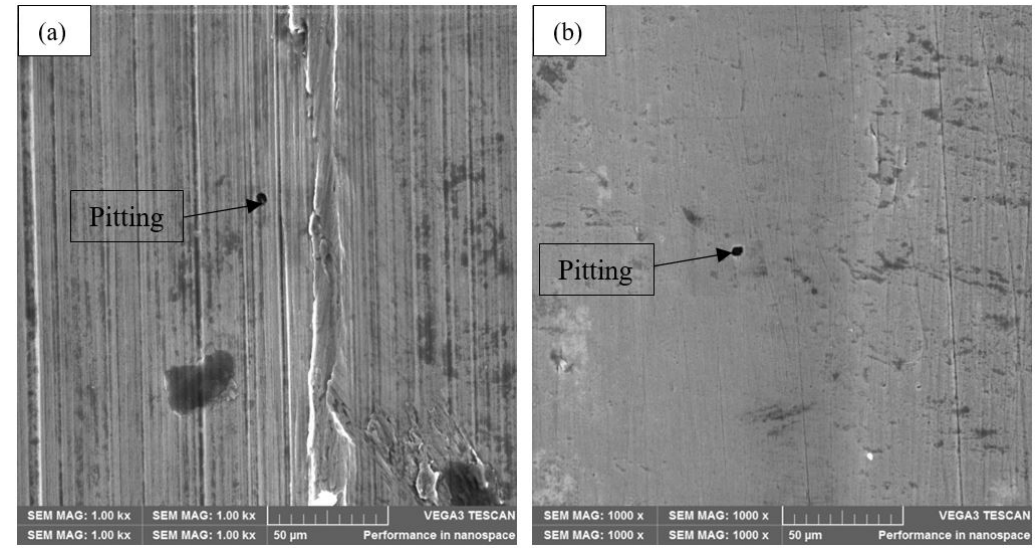

Figure 18. Samples of tests 3 (a) and $3 \mathrm{P}(\mathrm{b})$ with $1000 \mathrm{X}$ magnification.
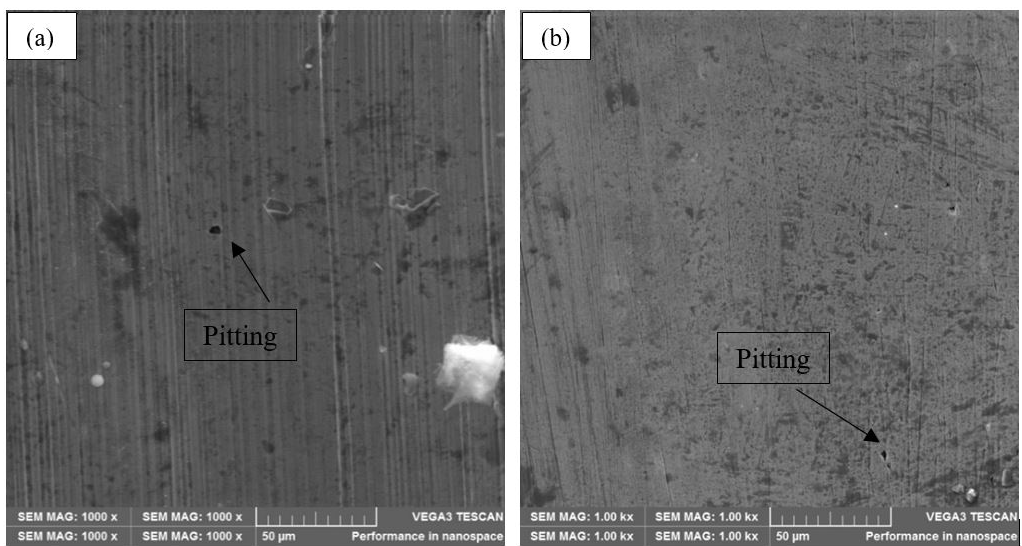

Figure 19. Samples of tests 4 (a) and $4 \mathrm{P}$ (b) with $1000 \mathrm{X}$ magnification. 


\section{Conclusion}

- The highest roughness values were found when the material was subjected to the most severe machining parameters, tool feed rate of $0.3 \mathrm{~mm} /$ rot and depth of cut of $3.0 \mathrm{~mm}$. And after polishing the samples, the roughness values decreased;

- Higher hardness values were found in measurements closer to the surface of the samples, and as the cutting parameters were increased, the hardness values also increased in addition to the affected distance. Having defined the association of the tool feed rate at $0.3 \mathrm{~mm}$ and depth of cut at $3.0 \mathrm{~mm} /$ rot. the one that had the greatest influence on the hardness variation and the association of $0.5 \mathrm{~mm}$ and $0.1 \mathrm{~mm} /$ rot was the one that less affected the ASTM F138 steel structure;

- The microstructure images identified a change in the shape of the austenitic grains, showing they had a lamellar appearance. They also identified that polishing had little influence on the structure provided by the cylindrical external turning, but material was removed, taking off a thin martensitic layer generated by the turning.

- Concerning the results of the machining tests, it can be observed that the feed rate of greater magnitude, $0.3 \mathrm{~mm} / \mathrm{rot}$, led to larger deformations on the surface of the samples in relation to the feed rate, $0.1 \mathrm{~mm} / \mathrm{rot}$, consequently increasing the hardness of the surface of the samples. However, the greater depth of cut, $3.0 \mathrm{~mm}$, generated a greater deformed layer thickness.

- The results of the corrosion tests indicate that surfaces subject to less severe machining values showed a higher resistance to corrosive attack and obtained a greater capacity of repassivation of the passive film.

- The polished surfaces were able to minimize the machining marks, but for processed samples with feed rates greater than $0.3 \mathrm{~mm} / \mathrm{rot}$, they still had marks from the previous process.

\section{References}

1. Bhattacharjee A, Amarnath L, Dutta K. Ratcheting behaviour of a sensitized non-conventional austenitic. Procedia Eng. 2017; 184:756-64.

2. De Vincentis NS, Avalos MC, Kliauga A, Brokmeier G, Bolmaro R. Strain path dependence of anisotropic microstructure evolution on low stacking fault energy F138 steel. Mater Sci Eng A. 2017;698:1-11.

3. Solomon N, Solomon I. Effect of deformation-induced phase transformation on AISI 316 stainless steel corrosion resistance. Eng Fail Anal. 2017;25:630-640.

4. Jinlong L, Hongyun L. Effects of strain and strain-induced $\alpha^{\prime}$-martensite on passive films in AISI 304 austenitic stainless steel. Mater Sci Eng C. 2014;34:484-90.

5. Ghatge D, Ramanujam R, Sudhakar R, Vignesh M. Improvement of machinability using eco-friendly cutting oil in turning duplex stainless steel. Mater Today-Proc. 2018;5(5):12303-10.

6. Ciftci I. Machining of austenitic stainless steels using CVD multilayer coated cemented carbide tools. Tribol Int. 2006;39(6):565-9.

7. Chagas G, Barbosa P, Barbosa C, Machado I. Thermal analysis of the chip formation in austenitic stainless steel. Procedia Cirp. 2013;8:293-8.

8. Maurotto A, Tsivoulas D, Gu Y, Burke M. Effects of machining abuse on the surface properties of AISI 316L stainless steel. Int J Press Vessels Piping. 2017;151:35-44.

9. Agrawal K, Aparna S. Limitations on the hardness increase in 316L stainless steel under dynamic plastic deformation. Mater Sci Eng A. 2018;687:306-12.

10. Bakrachevska E. Analysis of corrosion resistance property of cold bended $316 \mathrm{~L}$ and $6 \mathrm{Mo}$ stainless steel pipes. [thesis]. Stavanger: University of Stavanger; 2014.

11. ASTM International. E10-01: Standard test method for brinell hardness of metallic materials. West Conshohocken, PA: ASTM International; 2004.

12. ABNT: Associação Brasileira de Normas Técnicas. NBR4287: Especificações Geométricas do Produto (GPS), Rugosidade: Método do perfil- termos, definições e parâmetros da rugosidade. Rio de Janeiro: ABNT; 2002.

13. ASTM International. E384-99: Microindentation Hardness of Materials. West Conshohocken, PA: ASTM International; 1999.

14. Aquino JM, Della Rovere CA, Kuri SE. Intergranular corrosion susceptibility in supermartensitic stainless steel weldments. Corros Sci. 2009;51:2316-23.

15. Man C, Dong C, Kong D, Wang L, Li X. Beneficial effect of reversed austenite on the intergranular corrosion resistance of martensitic stainless steel. Corros Sci. 2019;151:108-121.

16. Rajaguru J, Arunachalam N. Investigation on machining induced surface and subsurface modifications on the stress corrosion crack growth behaviour of super duplex stainless steel. Corros Sci. 2018;141:230-42.

17. Bissey-Breton S, Vignal V, Herbst F, Coudert J. Influence of machining on the microstructure, mechanical properties and corrosion behaviour of a low carbon martensitic stainless steel. Procedia Cirp. 2017;46:331-5.

18. Hong L, Huaizhi S, Baosong L, Guobing Y. Electrochemical and passive behaviour of tin alloyed ferritic stainless steel in concrete environment. Appl Surf Sci. 2018;439:232-9. 